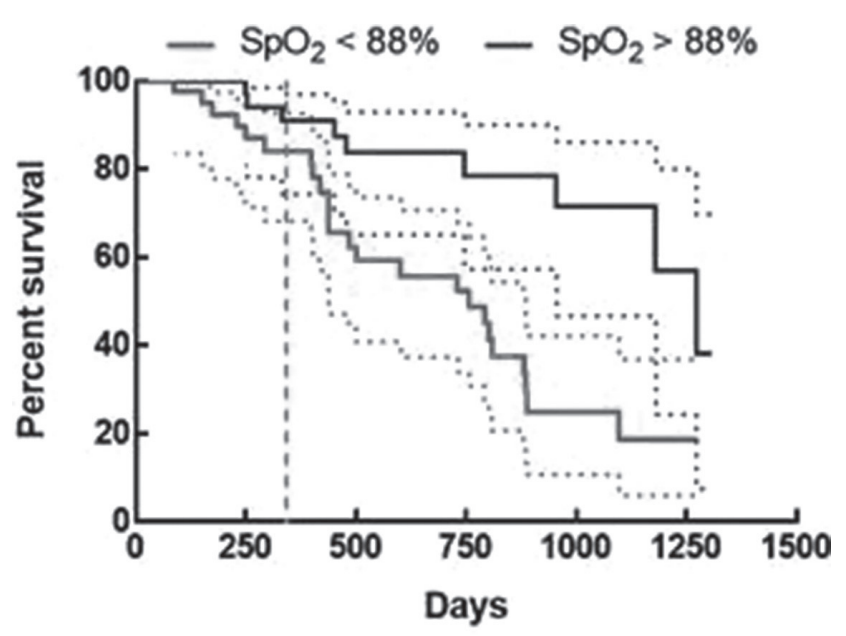

Abstract P278 Figure 1 Kaplan-Metre survival curve for $\mathrm{SpO}_{2}$ min $<88 \%$ (red line) and $>88 \%$ (blue line). The green dashed line plotted shows survival of 365 days of $90 \%$. The bkue and red dotted lines are the $95 \%$ confidence interval for survival.

For an $\mathrm{SpO}_{2}$, min cut-off of $85 \%$, survival was $791(<85 \%)$ and $1181(>85 \%)$ days ( $p<0.05$; hazard ratio 3.356). With a cut-off of $88 \%$, survival was $757(<88 \%)$ and $1272(>88 \%)$ days $(\mathrm{p}=0.0012$; hazard ratio 3.161$)$. Survival at one year as $84 \%(<88 \%)$ and 91\% (>88\%) (Figure).

Distanced walked was not significantly different at cut-offs of $250 \mathrm{~m}$ or $350 \mathrm{~m}$.

Conclusions From this retrospective analysis, these results suggest that a cut-off for $\mathrm{SpO}_{2}$, min of $88 \%$ may be a useful predictor of survival at one year and in the longer term. Distance walked appears to contribute little to prediction of survival.

\section{P279 FEASIBILITY OF AN 8-WEEK OUT-PATIENT INSPIRATORY MUSCLE TRAINING (IMT) PROGRAMME IN PATIENTS WITH INTERSTITIAL LUNG DISEASE (ILD)}

${ }^{1} \mathrm{M}$ Koulopoulou, ${ }^{2} \mathrm{~S}$ Greenwood, ${ }^{2} \mathrm{C}$ Reilly, ${ }^{3} \mathrm{~F}$ Chua. ${ }^{1}$ Kingston University and St George's University of London, London, UK; ${ }^{2}$ King's College Hospital, London, UK; ${ }^{3}$ Royal Brompton Hospital, London, UK

\subsection{6/thoraxjnl-2016-209333.422}

Introduction The 2013 ATS/ERS guidelines on Pulmonary Rehabilitation suggest that IMT confers significant improvements in various outcomes in chronic obstructive pulmonary disease (COPD). IMT may play a role in dyspnoea and exercise tolerance in patients with ILD; Feasibility of delivering an outpatient IMT programme for ILD is yet to be determined.

Aim The aim of this pilot-feasibility study was to assess the acceptability and practicality of delivering an outpatient IMT programme in patients with ILD.

Methods Radomised trial recruited 17 patients with ILD from St George's Hospital chest clinic, London. Inclusion criteria were: ILD patients on stable medical treatment, with breathlessness MRC >3. 9 patients (intervention group); median (IQR) DLco predicted $44[28,45] \%$ underwent H-IMT; exercised at $60 \%$ of sustained maximal inspiratory pressure (SMIP); 8 patients (control group) median (IQR) DLco 39.5 [24, 60]\% underwent low intensity IMT (S-IMT); exercised at $15 \%$ of SMIP. Data collection included pre-post IMT in the following outcomes: six minute walk test (6MWT), quality of life (SGRQ-I), dyspnoea:
(Borg and Dyspnoea-12), maximal inspiratory pressure (MIP) and sniff nasal inspiratory pressure (Sniff-P).

Results 76 patients were screened; 26 meet the criteria to participate. $19(75 \%)$ consented to partake in the study. Completion rates for HIIMT was $89 \%(8 / 9)$, and $75 \%(6 / 8)$ for LIMT. HIIMT-G exhibited significantly higher MIP compared to LI-IMT-G $(p=0.043)$.There were no significant between-group differences in the other parameters. Within group analysis demonstrated that: HI-IMT improved significantly on 6MWT, MIP, Sniff-P, and SGRQ-I. LI-IMT, improved significantly on 6MWT, Borg and D12 (Table 1).

Conclusions HI-IMT was well tolerated and accepted by ILD patients, and it demonstrated improvements in measured outcomes; IMT requires close monitoring and input to enhance motivation; this type of training can only fit small groups of patients and the extra cost should be considered. IMT may be an alternative option to exercise training for ILD patients to ameliorate dyspnoea and combat exercise deconditioning; larger studies are required to explore effectiveness and cost effectiveness of IMT in ILD.

\begin{tabular}{|c|c|c|c|c|c|}
\hline & $\begin{array}{l}\text { Training group } \\
(\mathrm{n}=9)\end{array}$ & & $\begin{array}{l}\text { Control group } \\
(n=8)\end{array}$ & & $\begin{array}{l}\text { Between group } \\
\text { changes }\end{array}$ \\
\hline & $\begin{array}{l}\text { Change from } \\
\text { baseline }\end{array}$ & $\begin{array}{l}P \\
\text { value }\end{array}$ & $\begin{array}{l}\text { Change from } \\
\text { baseline }\end{array}$ & $\begin{array}{l}P \\
\text { value }\end{array}$ & $P$ value \\
\hline $\begin{array}{l}\text { 6MWT-D } \\
\text { (m) }\end{array}$ & $\begin{array}{l}57.50[11.25, \\
120]\end{array}$ & $0.027^{*}$ & $60[30,98.5]$ & $0.027^{*}$ & 0.9 \\
\hline Borg-D & $\begin{array}{l}-1.00[-1.00 \\
(-2.00)]\end{array}$ & 0.059 & $\begin{array}{l}-1.5[0.00 \\
(-2.00)]\end{array}$ & $0.015^{*}$ & 0.9 \\
\hline (D-12)-D & $\begin{array}{l}-1.00[-0.75, \\
4.00]\end{array}$ & 0.462 & $\begin{array}{l}-1.5[-1.00 \\
(-11.00)]\end{array}$ & $0.026^{*}$ & 0.282 \\
\hline $\begin{array}{l}\text { MIP-D } \\
\left(\mathrm{cmH}_{2} \mathrm{O}\right)\end{array}$ & $15.00[11,25.50]$ & $0.012^{*}$ & $\begin{array}{l}3.50[-2.50, \\
11.50]\end{array}$ & 0.207 & $0.043^{*}$ \\
\hline $\begin{array}{l}\text { Sniff-D } \\
\left(\mathrm{cmH}_{2} \mathrm{O}\right)\end{array}$ & $\begin{array}{l}15.00[5.50, \\
26.00]\end{array}$ & $0.025^{*}$ & $\begin{array}{l}4.40[3.25, \\
11.25]\end{array}$ & $0.027^{*}$ & 0.142 \\
\hline CAT-D & $\begin{array}{l}-0.50[-4.75, \\
1.50]\end{array}$ & 0.248 & $\begin{array}{l}-1.50[-4.25, \\
2.50]\end{array}$ & 0.500 & 0.9 \\
\hline (SGQ-I)-D & $\begin{array}{l}-10.61[-14.5 \\
(-5.05)]\end{array}$ & $0.025^{*}$ & $\begin{array}{l}-8.8[-27.1, \\
(-2.9)]\end{array}$ & 0.075 & 0.9 \\
\hline
\end{tabular}

\section{P280 PULMONARY REHABILITATION (PR) FOR INTERSTITIAL LUNG DISEASE (ILD). DO PATIENTS' PERCEPTIONS MATCH FUNCTIONAL OUTCOMES?}

L Stanley, C Cobbett, E Morris, D Gibson, SV Fletcher. University Hospital Southampton NHS Foundation Trust, Southampton, UK

\subsection{6/thoraxjn--2016-209333.423}

Introduction ILD refers to a group of fibrotic lung conditions that differ in terms of treatment, prognosis and association. The NICE quality statement (2015) supports PR for patients with IPF, the most common form of ILD. There is no clear guidance for delivery of PR to ILD patients, so current practice is to extrapolate from the benefits of PR in COPD (Spruit et al, 2013), despite the differing pathophysiology.

Aim The focus of the study was to observe the patients' perceptions of a modified ILD PR programme against functional and health related quantitative measures. 